\title{
Effect of ultrasound-guided percutaneous neuromodulation in ankle instability: a case study
}

\author{
Rodríguez Rosal M. ${ }^{1}$ Sánchez Sixto A. ${ }^{1}$ Álvarez Barbosa F. ${ }^{1}$ Yáñez Álvarez A. ${ }^{2}$ \\ ${ }^{1}$ CEU Cardenal Spínola, Sevilla, Spain \\ 2 Universidad de Sevilla, Sevilla, Spain
}

Rev Fisioter Invasiva 2019;2:100-101.

\begin{abstract}
Keywords

- percutaneous neuromodulation

- ankle

- proception

- tibial nerve

Background and Aims Ankle proprioception can be tested in many ways. Some studies have found improvements in individuals with chronic ankle instability after receiving treatment and training proprioceptive acuity and speed. Currently, there is a scarcity of evidence concerning percutaneous neuromodulation. The first findings were reported in the post-surgical stage after total knee arthroplasty and in neural improvements and symptoms in patients with hyperactive bladder.

Aim To evaluate the effectiveness of percutaneous neuromodulation on the tibial nerve for the improvement of various proprioception parameters in patients with chronic ankle instability.

Material and Methods Five men (age: $24.8 \pm 4.9$ years; height: $1.78 \pm 0.08 \mathrm{~m}$; weight: $86 \pm 9.8 \mathrm{~kg}$ ) with chronic ankle instability, who regularly practiced sports activities participated in the present study. People who had undergone an injury in the previous three months were excluded from the speed. Currently, there is a scarcity of evidence concerning test before and immediately after percutaneous neuromodulation. A single leg balance test was performed with eyes open and closed, maintaining the single-legged position on a force plate during 30 seconds (Accupower; AMTI, Watertown, MA) registering $1000 \mathrm{~Hz}$. The displacement of the center of pressure (DOT) was determined based on the distances of its antero-posterior axes (DOT_AP) and medio-lateral (DOT_ML). Furthermore, the amplitudes of anteroposterior and mediolateral displacement were evaluated (ACPap and ACPml). The posterior tibial nerve was stimulated under ultrasound guidance using a $100 \mathrm{Vpp}$ current, with a pulse width of $250 \mu \mathrm{s}$ and a repetition frequency of 2 to $10 \mathrm{~Hz}$. The process was performed on three occasions during 30 seconds, with an intensity that was acknowledged by the patient but which did not go beyond a score of 3 in the visual analog scale (VAS). The means and standard deviations were calculated for all variables. The effect size was calculated establishing the confidence interval at $90 \%$ and the probability of the change being significant was qualitatively calculated.

Results A decrease was found in the ACPap (Pre-test eyes open: $5.42 \pm 0.62$ and eyes closed: $15.99 \pm 0.60$; Post-test eyes open $4.05 \pm 0.36$ and eyes closed $10.33 \pm 0.49$ ) after the neuromodulation intervention on the tibial nerve. This was a significant change and a "possible" effect size was found in the closed eyes condition $(-0.54 ; \pm 0.72)$, according to Hopkins. For the remaining variables, no significant differences were observed.
\end{abstract}

DOI https://doi.org/ $10.1055 / \mathrm{s}-0039-3401876$. ISSN 2386-4591.
Copyright $\odot 2019$ by Thieme Revinter Publicações Ltda, Rio de Janeiro, Brazil
License terms

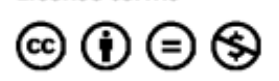


Conclusions A decreased displacement of the center of mass was found in the anteroposterior axis after performing the neuromodulation technique on the tibial nerve in patients with chronic ankle instability. 